\title{
The Effect of Submucosal Injection of Plasma-Rich Platelets on Blood Inflammatory Markers for Patients with Bimaxillary Protrusion Undergoing Orthodontic Treatment
}

\author{
Trefa Mohammed Ali Mahmood $\mathbb{D}^{1}$ and Omar Fawzi Chawshli ${ }^{2}$ \\ ${ }^{1}$ Department of Pedodontics, Orthodontics and Preventive Dentistry, College of Dentistry, University of Sulaimani, \\ Sulaymaniyah, Kurdistan Region, Iraq \\ ${ }^{2}$ Department of Pedodontics, Orthodontics and Preventive Dentistry, College of Dentistry, Hawler Medical University, Erbil, \\ Kurdistan Region, Iraq \\ Correspondence should be addressed to Trefa Mohammed Ali Mahmood; trefa.ali@univsul.edu.iq
}

Received 18 May 2019; Revised 6 August 2019; Accepted 3 September 2019; Published 1 October 2019

Academic Editor: B. L. Slomiany

Copyright (C) 2019 Trefa Mohammed Ali Mahmood and Omar Fawzi Chawshli. This is an open access article distributed under the Creative Commons Attribution License, which permits unrestricted use, distribution, and reproduction in any medium, provided the original work is properly cited.

\begin{abstract}
Objectives. The present study aims to reveal the systemic effects of submucosal injection of plasma-rich platelets (PRP) on blood inflammatory markers which was used in an attempt to reduce the retraction time of the upper canine following extraction of upper maxillary premolars for patients with bimaxillary protrusion. Hypothesis. No change on comparing the values of blood inflammatory markers before and after submucosal injection of PRP. Methods. Eighteen female patients with bimaxillary protusion were selected from patients seeking orthodontic treatment from the College of Dentistry/University of Sulaimai, whose maxillary and mandibular first premolars were decided to be extracted after proper diagnosis. Thirty-three blood markers (twenty hematological and thirteen biochemical markers) were estimated before orthodontic bracketing, 24 hours and 7 days following submucosal injection of PRP $(5 \mathrm{cc})$ to reveal the systematic effect of PRP on blood inflammatory markers that were used in an attempt to reduce the retraction time of the upper canine following extraction of upper maxillary premolars for patients with bimaxillary protrusion. Results. The results indicate nonsignificant differences in the values of all blood markers except for gamma GT (GGT), PDWa, serum albumin, serum total protein, and total calcium. Gamma level significantly increased for both test intervals. On the other hand, there was a significant drop in the value of PDWa while for alkaline phosphatase, there was a drop within the first $24 \mathrm{hr}$ of PRP injection while after 7 days the value was significantly increased. On the other hand, there was a drop in the level of serum albumin, while there was an increase in the serum total protein and total calcium. Conclusion. Submucosal injection of PRP could lead to systematic alteration of blood parameters including ALK phosphatase, gamma GT, serum albumin, and serum total protein, which may be related to liver function in addition to increase in the level of PDWa and serum calcium. We present evidence that PRP contains and may trigger systemic effect. Thus, further investigation is recommended to follow up the patient for a longer period of time and on a larger sample. This trial is registered with U1111-1221-8829 by Sri Lanka Clinical Trial Registry, SLCTR/2018/040, and No. 64 on $6^{\text {th }}$ August 2018 at the local clinical studies database, College of Dentistry.
\end{abstract}

\section{Introduction}

Since the inception of the practice of orthodontics, one of the domains in the research has been the tooth movement and associated biological reactions. Research has been done to study various approaches to achieve tooth movement with most physiological manner but with maximum pace [1].
PRP has recently been considered as an orthobiological adjuvant treatment [2], currently used in different medical fields. The interest in the application of PRP in dermatology has recently increased as it is being used in several different applications such as in tissue regeneration, wound healing, scar revision, skin rejuvenating effects, and alopecia [3]. PRP has the potential and capability to promote periodontal 
regeneration through various mechanisms. The effect of PRP in localized acceleration of tooth movement is dependent on the concentration used. However, the method of synthesis is critical to the success of PRP-based acceleration of tooth movement. The use of injectable PRP at a different stage of orthodontic treatment can improve the quality of the treatment outcome by influencing the bone quality and enhancing the rate of tooth movement [1].

PRP is defined as an autologous concentration of platelets in a small volume of plasma and is considered to be a rich source of autologous growth factors (GFs) [4]. GFs are natural biologic mediators that regulate key cellular events that are part of the process of tissue repair and regeneration. After binding of GFs to specific cell membrane receptors of target cells, intracellular signaling pathways are induced; this typically results in the activation of genes that may ultimately change the cellular activity and phenotype. However, the effect of each GF is regulated through a complex system of feedback loops, which involve other GFs, enzymes, and binding proteins. Recent advances in the areas of cellular and molecular biology have allowed better understanding of the functions of GFs. In vitro and in vivo studies have confirmed that GFs can enhance the capacity of tissues to regenerate by regulating cell chemoattraction, differentiation, and proliferation [5].

PRP components interact with cells involved in the immune response and inflammation, angiogenesis, cell migration and differentiation, and anabolism and catabolism of the extracellular matrix. This list of PRP elements is not comprehensive: interleukin $1 \mathrm{~b}(1 \mathrm{~b})$; tumor necrosis factor (TNF); platelet-derived growth factor (PDGF); tissue growth factor (TGF); vascular endothelial growth factor (VEGF); and fibroblastic growth factor (FGF) [6]. There are several systemic biomarkers that could be related to orthodontic treatment. For instance, according to Yashin et al. [7], there were significant increases in hs-CRP level, WBC count, and neutrophil count while a significant decrease in $\mathrm{Na}$ level. K level was significantly decreased on day one. Indicating a systemic immune response develops against therapy in patients undergoing fixed orthodontic therapy. Ileri et al. [8] concluded that piezocision procedure might be related to transitory bacteremia. Hence, orthodontists should consider the possibility of bacterial endocarditis in at-risk patients when piezocision is part of the treatment plan, while Azeem et al. [9] revealed that the microosteoperforation technique is not related to transitory bacteremia.

\section{Methodology}

This study was conducted in the Department of Pedodontics, Orthodontics, and Preventive Dentistry, College of Dentistry, University of Sulaimani, with the corporation Shar Medical Center Library.

2.1. The Sample. Eighteen females with bimaxillary protrusion were selected from patients seeking orthodontic treatment, whose maxillary and mandibular first premolars were decided to be extracted after proper diagnosis using study models, digital cephalomerty, orthopantomograph, and CBCT; all the cases were evaluated with the supervisor (Orthodontist).

The Simplified Oral Hygiene Index (OHI-S) was used to estimate the oral health of the selected patients which is different from the original Oral Hygiene Index (OHI) in the number of the tooth surfaces scored (6 rather than 12), the method of selecting the surfaces to be scored, and the scores which can be obtained. The criteria used for assigning scores to the tooth surfaces are the same as those used for the OHI.

The OHI-S, like the OHI, has two components: the Debris Index and the Calculus Index. Each of these indexes, in turn, is based on numerical determinations representing the amount of debris or calculus found on the preselected tooth surfaces [10]. Zero oral hygiene indices were scored for all participants prior to begin the sequences of treatment.

2.2. Design. Experimental study (split mouth) was employed in this study. Patients were considered eligible for the study if they meet the following inclusion criteria:

(1) Aged between 18 and 26 years

(2) Bimaxillary protrusion

(3) Minimum crowding (less than $2 \mathrm{~mm}$ ) or minimum spacing (less than $4 \mathrm{~mm}$ )

(4) Indication for extraction of upper and lower first premolars

(5) The feasibility of bonding brackets

(6) No previous orthodontic treatment

(7) No systemic diseases

(8) No smoking

(9) Good oral hygiene

The exclusion criteria were as follows:

(1) Patients with severe tooth displacement (e.g., ectopic canine)

(2) Those reporting the use of medications throughout the study

The rights of patients were protected and the purpose and methods of the study were completely explained to the patients and parents; informed consent was obtained from each blood inflammatory marker. Blood samples $(5 \mathrm{ml})$ were drawn at the baseline on day zero, and after 24 hours of acceleration (beginning retraction) [11], the following blood tests were performed [7]:

(1) C-reactive protein (CRP)

(2) CBC parameters

(3) Levels of aspartate aminotransferase (AST)

(4) Alanine aminotransferase (ALT)

(5) Gamma glutamyl transferase (GGT)

(6) Alkaline phosphatase (ALP)

(7) Urea 

(8) Creatinine
(9) Sodium $(\mathrm{Na})$
(10) Potassium (K)
(11) Calcium (Ca)
(12) Total protein (TP)
(13) Albumin (Alb)

These tests were performed at Shar Medical Center laboratory before acceleration ( $\mathrm{Tb} 0$ ) and 24 hours ( $\mathrm{Tb} 1)$ and 7 days (Tb7) following acceleration.

\section{Clinical Procedure}

Five to seven days after first premolars extraction, fixed orthodontic appliances of MBT prescription 0.022-inch slot height were bonded. Then, a 0.014-inch NiTi archwire was inserted and tied to each bracket using ligature wires.

Arch wire sequences used were 0.014 -inch NiTi followed by 0.018 inch $\mathrm{NiTi}, 0.017-0.025$ inch $\mathrm{NiTi}$, and finally 0.017-0.025 stainless steel. Before retraction self-drilling temporary anchorage devices of $10 \mathrm{~mm}$ length and $1.6 \mathrm{~mm}$ diameter were inserted with hand drill between the upper second premolar and the upper first molar for both sides as an anchorage for retraction force, as well as for the lower arch.

At this stage, upper canines were retracted with the use of maximum anchorage (TADs). The right side composed the study group, whereas the left side served as the control group.

The retraction phase was initiated after PRP injection on the experimental side (right), using elastomeric chains with a force of $150 \mathrm{gm}$, translation movement according to Kanuru et al. [12], measured using stress and tension gauge dial type (Dentaurum).

For the control side, retraction was started at the same time with the same mechanics. Patients were examined at two week intervals, and the elastomeric chains were replaced at each appointment until ideal class I canine relationships were established (bracket system).

Ultraesthetic brackets, archwires, and accessories were used; sapphire bracket (MBT Slot 0.022 inch slot height) from DW Orthoworld Company, which totally blends with the dental structure, was used. Mimetic is designed with advanced 3D technology to offer great adaptation and comfort for the patient. Bonding was with OrthoFlow compsite of the same company that does not require any bonding agent on the enamel surface in order to meet both clinical and aesthetic needs (Figure 1).

\section{PRP Preparation}

The variation of platelets and other blood component concentrations between commercial PRP kits may affect clinical treatment outcomes [13]. A $30 \mathrm{cc}$ venous blood draw will yield 3-5cc of PRP [14]. There are many ways of preparing PRP. It can be prepared by the PRP method or by the buffy-coat method. In this study, we will use the PRP method, using an initial centrifuge to separate red blood cells

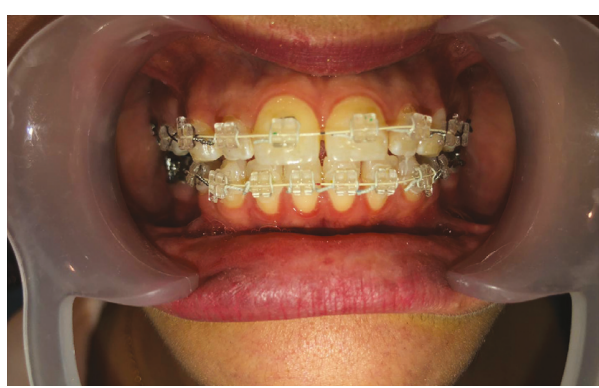

FIGURE 1: Bracketing.

(RBC) followed by a second centrifuge to concentrate platelets, which are suspended in the smallest final plasma volume. Blood is initially collected in PRP tubes that contain anticoagulant citrate dextrose (ACD). The first spin step is performed at constant acceleration to separate RBCs from the remaining blood volume for 9 minutes at about $2000 \mathrm{rpm}$. After the first spin step, blood will separate into three layers: an upper layer that contains mostly platelets and $\mathrm{WBC}$, an intermediate thin layer that is known as the buffy coat and rich in WBCs, and a bottom layer that consists mostly of RBCs. For the production of pure PRP, the upper layer and superficial buffy coat are transferred to an empty sterile tube, and the second spin step is then performed for 10 minutes at $3870 \mathrm{rpm}$; thus, the lower $1 / 3 \mathrm{rd}$ will be the PRP (platelet-rich plasma). So, the procedure, in detail, involves a $35 \mathrm{cc}$ of venous blood draw using aseptic technique from median cubital vein of the patient. A butterfly needle was used in efforts of avoiding irritation and trauma to the platelets, which are in a resting state. ROTIXA 500 RS Hettich floor-standing centrifuge (Figure 2), producing high concentration PRP (5 times the concentration in whole blood), an initial centrifuge to separate red blood cells (RBC) is followed by a second centrifuge to concentrate platelets, which are suspended in the smallest final plasma volume. Blood is initially collected in PRP tubes that contain anticoagulant citrate dextrose (ACD). The first spin step is performed at constant acceleration to separate RBCs from the remaining blood volume for 9 minutes at about $2000 \mathrm{rpm}$. After the first spin step, blood will separate into three layers: an upper layer that contains mostly platelets and WBC, an intermediate thin layer that is known as the buffy coat and rich in WBCs, and a bottom layer that consists mostly of RBCs. For the production of pure PRP, upper layer and superficial buffy coat are transferred to an empty sterile tube, and the second spin step is then performed for 10 minutes at $3870 \mathrm{rpm}$; thus, the lower $1 / 3 \mathrm{rd}$ will be the PRP (platelet-rich plasma).

\section{Site of Injection}

Five cubic centimeters of PRP was injected by means of a microsyringe into the buccal and palatal vestibular mucosa distally through the attached gingiva into the oral mucosa to the root of the upper right canines of each patient under local anesthesia. All injections were volumetrically equivalent. Injections were performed only once on day zero of 


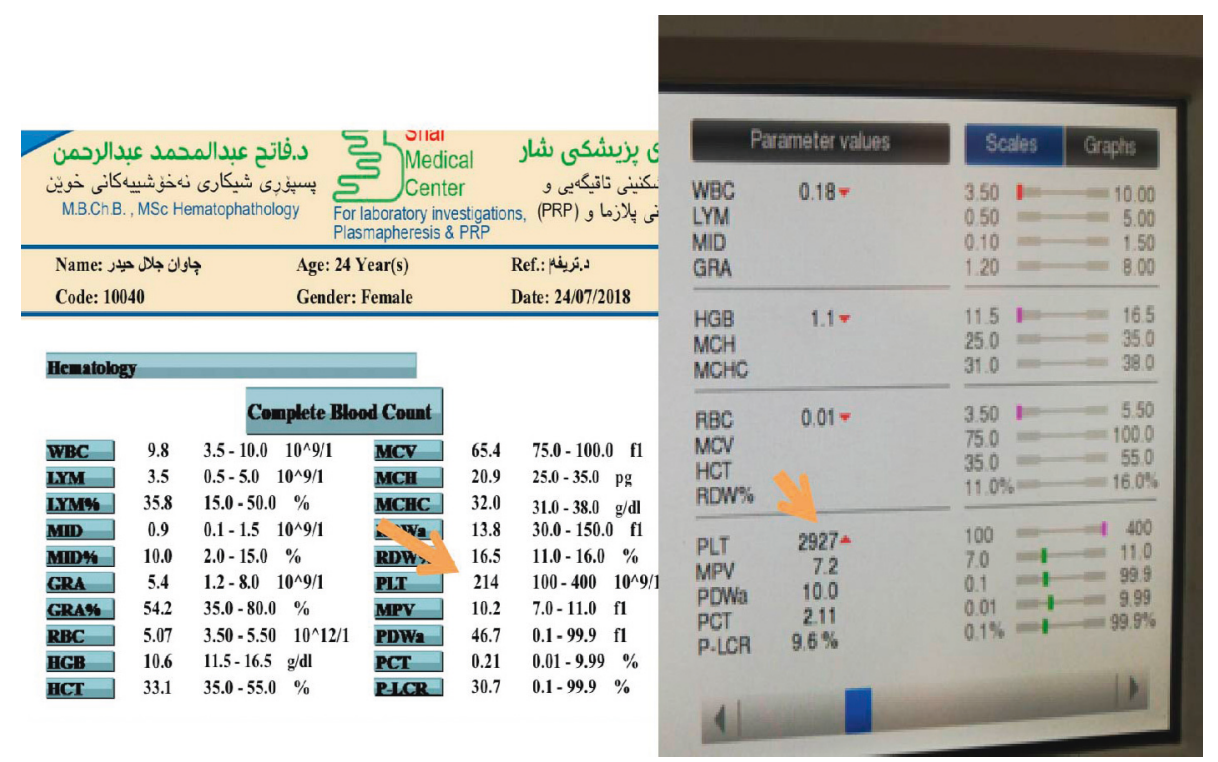

FIGURE 2: ROTIXA 500 RS Hettich floor-standing centrifuge was used, producing high concentration PRP (5 times the concentration in whole blood).

retraction and not repeated again (as illustrated in Figures 3 and 4).

Before the injection of PRP, local anesthesia (Xylocaine) was used at the target sites for $t$ pain control. It is a submucosal injection rather than a subperiosteal injection. It is just similar to the injection of local anesthesia, and it has no certain injection pattern (six injections, each one was $0.8 \mathrm{cc}$ ). Acetaminophen (500 mg) was prescribed for the postinjection pain control. Nonsteroidal antiinflammatory drugs will neutralize the effects of PRP and were not used for the postinjection pain control [15].

\section{Measurements}

(1) Blood parameter test before acceleration (Tb0), following 24 hours of acceleration (Tb1) and 7 days following acceleration (Tb7). Values were analyzed using the SPSS (Statistical Package for Social Science) for Windows.

(2) Descriptive statistics consisting of mean, standard deviation (SD), and minimum (Min) and maximum (Max) for all the values at $\mathrm{Tb} 0, \mathrm{~Tb} 1$, and $\mathrm{Tb} 7$ (Table 1).

(3) One-way repeated measures analysis of variance was used, and $F$-ratio was used to compare the 3 groups of variables (Table 2).

\section{Results}

Descriptive statistical analysis including mean, minimum, maximum, and standard deviation is summarized in Table 1. The results indicate nonsignificant differences in the values of all blood markers except for PDWa, gamma GT (GGT), ALK phosphatase, S. albumin, S. total protein, and total calcium.
The gamma level significantly increased from $13.1 \mathrm{IU} / \mathrm{L}$ to $22.1 \mathrm{IU} / \mathrm{L}$ at $\mathrm{Tb} 1$ and $23.8 \mathrm{IU} / \mathrm{L}$ at $\mathrm{Tb} 7$ ( $p$ value 0.00001 ). On the other hand, there was a significant drop in the value of PDWa from $21.3 \mathrm{fl}$ to $12.3 \mathrm{fl}$ at Tb1 and $12.4 \mathrm{fl}$ at Tb7 ( $p$ value 0.018 ), while for alkaline phosphatase there was a drop within the first $24 \mathrm{hr}$ after PRP injection from $56.1 \mathrm{IU} / \mathrm{L}$ to $49.1 \mathrm{IU} / \mathrm{L}$ at $\mathrm{Tb} 1$, while after 7 days the value was significantly increased to $58.7 \mathrm{IU} / \mathrm{L}$ ( $p$ value 0.00001 ).

On the other hand, there was a drop in the level of serum albumin from $4.48 \mathrm{~g} / \mathrm{dl}$ to $3.98 \mathrm{~g} / \mathrm{dl}$ at $\mathrm{Tb} 1$ and $4.01 \mathrm{~g} / \mathrm{dl}$ at Tb7 ( $p$ value 0.0035 ), while there was an increase in the serum total protein from $7.08 \mathrm{~g} / \mathrm{dl}$ to $9.44 \mathrm{~g} / \mathrm{dl}$ at $\mathrm{Tb} 1$ and $9.02 \mathrm{~g} / \mathrm{dl}$ at $\mathrm{Tb} 7$ ( $p$ value 0.00001 ). Again, for the total calcium level, there was a significant increase from $9.3 \mathrm{mg} / \mathrm{dl}$ to $9.59 \mathrm{mg} / \mathrm{dl}$ at $\mathrm{Tb} 1$ and $9.65 \mathrm{mg} / \mathrm{dl}$ at $\mathrm{Tb} 7$ ( $p$ value 0.049 ), although all the values remain within the normal level except for serum albumin as shown in Table 2.

\section{Discussion}

Only females were included in this study, as $65 \%$ of patients seeking orthodontic treatment were females according to a study done in Sulaimani City by Amin et al., which also comes in accordance with other studies [16], also in an attempt to reduce bias related to biological responses that differ between genders.

As previous studies revealed that conventional orthodontic treatment is not associated with systemic immune response at any time points; for this reason, we do not include a control group in an attempt to reduce time and effort [17]. Besides, another study assessed the effects of fixed orthodontic therapy on high-sensitivity C-reactive protein (hs-CRP) level, $\mathrm{CBC}$ parameters, and levels of aspartate aminotransferase (AST) and alanine aminotransferase (ALT), gamma glutamyl transferase (GGT), alkaline phosphatase (ALP), urea, creatinine, sodium $(\mathrm{Na})$, potassium $(\mathrm{K})$, calcium $(\mathrm{Ca})$, total protein (TP), and albumin (Alb), and their results confirm that an 


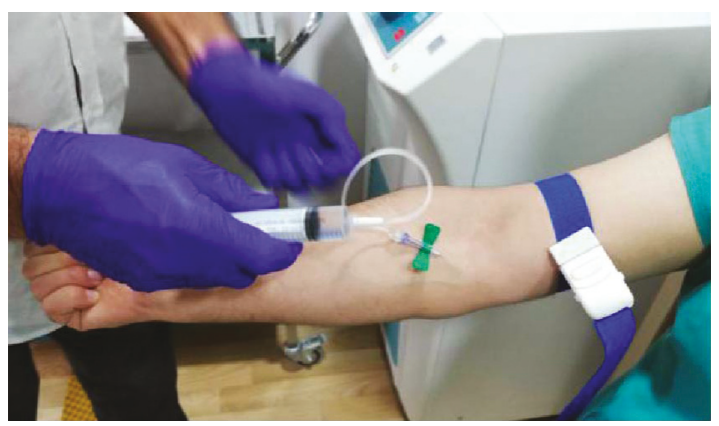

(a)

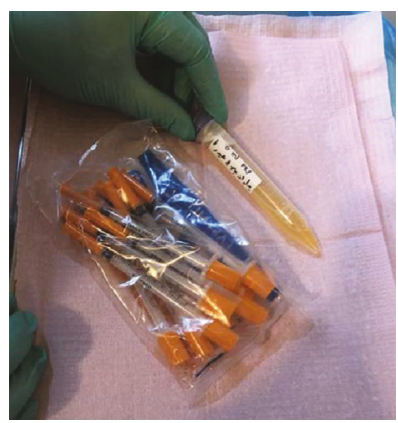

(b)

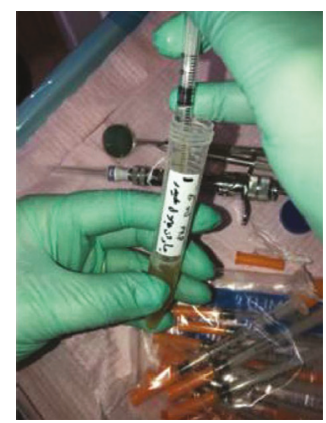

(c)

FIGURE 3: PRP preparation.
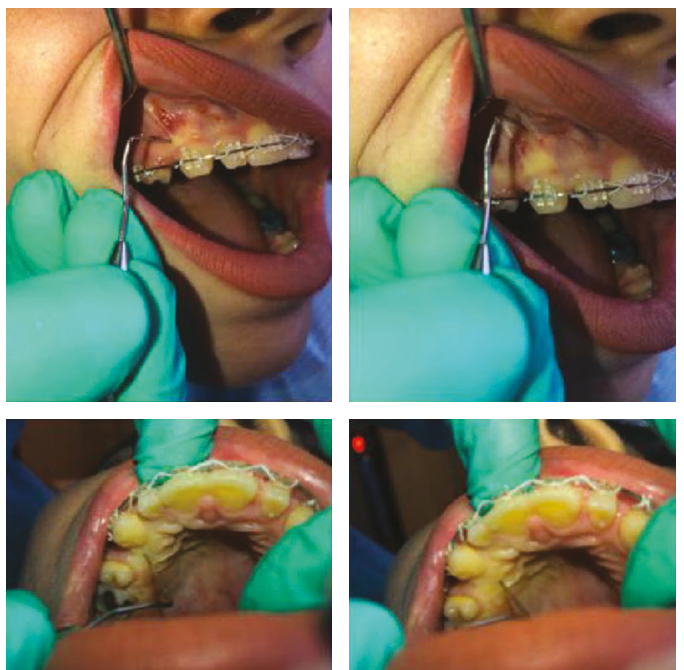

(a)
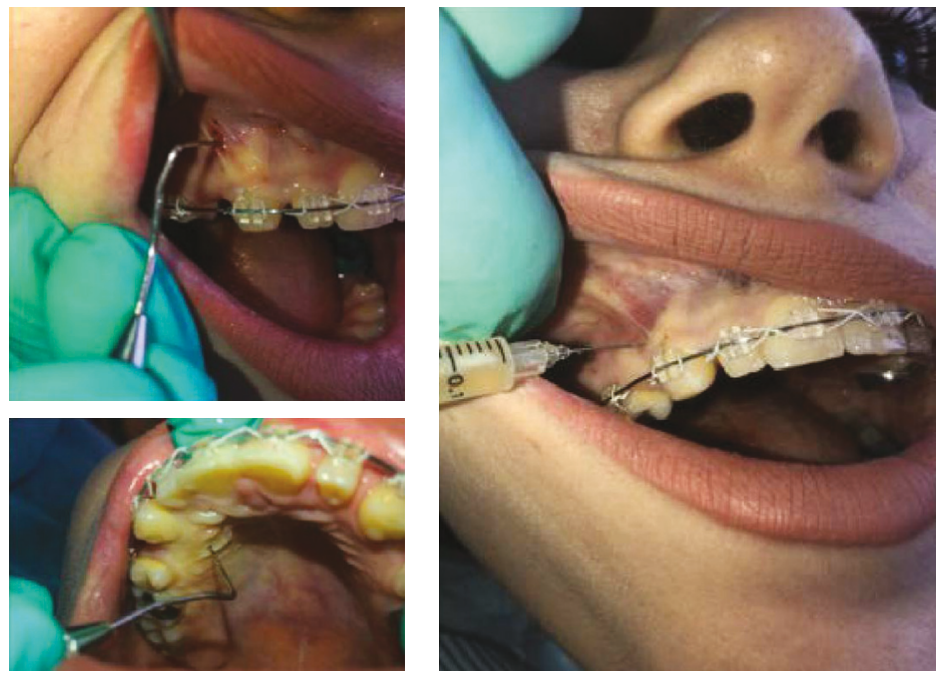

(b)

FIGURE 4: Site of PRP injection and force application.

elevation in serum hs-CRP levels and neutrophil-lymphocyte ratio within first 3 months [18] does not have effects on the blood parameters that were assessed in our study (PDWa, gamma GT (GGT), ALK phosphatase, S. albumin, S. total protein, and total calcium). Thus, it gives a proof that our result is solely related to PRP injection.

PRP is injected submucosally not subperiosteally following the standardization and the proposal of the use of PRP in orthodontics according to previous studies [15].

Starting with gamma-glutamyl transferase (GGT), there was a significant increase for both $\mathrm{Tb} 1$ and $\mathrm{Tb} 7$ within the normal range, but still it is an interesting finding especially when it comes with significant decrease of serum albumin level.However, GGT's predictive utility applies well beyond liver disease, and elevated GGT is linked to increased risk to a multitude of diseases and conditions, including cardiovascular disease, diabetes, metabolic syndrome, and all-cause mortality [19].

Low antioxidant defenses are also correlated with elevated GGT [20]. GGT is an enzyme found in cell membranes of many tissues mainly in the liver, kidney, and pancreas. It is also found in other tissues including the intestine, spleen, heart, brain, and seminal vesicles. The highest concentration is in the kidney, but the liver is considered the source of normal enzyme activity [21].

Secondly, the red cell distribution width (RCDW) test is used to study the distribution of RBCs not their actual size. Levels outside of the normal range can indicate conditions such as anemia, malnutrition, and liver disease [21].

Thirdly, the alkaline phosphatase (ALP) level in healthy adults should be $20-140 \mathrm{U} / \mathrm{L}$. As ALP is most abundant in the bones and liver, elevated ALP levels are generally a sign of a liver or bone condition. An obstruction of the liver or damage to it will cause ALP levels to rise. This will also occur if there is an increase in bone cell activity [22].

Fourthly, the normal range of serum albumin is 3.5 to $5.2 \mathrm{~g} / \mathrm{dl}$. Serum albumin measures the amount of albumin in the clear liquid portion of blood. Conditions associated with "low" levels of albumin are as follows: ascites, burns, glomerulonephritis, liver disease (hepatitis or cirrhosis), malabsorption syndrome (e.g., Crohn's disease, celiac disease, or Whipple disease), and malnutrition. Serum albumin is a multifunctional circulatory protein, and its concentration is influenced by several factors including its synthesis rate, 
TABLe 1: Descriptive statistical analysis.

\begin{tabular}{|c|c|c|c|c|c|c|c|c|c|c|c|c|}
\hline \multirow{2}{*}{ Blood markers } & \multicolumn{4}{|c|}{ Initial (Tb0) } & \multicolumn{4}{|c|}{ After $24 \mathrm{hr}$ (Tb1) } & \multicolumn{4}{|c|}{ After 7 days (Tb7) } \\
\hline & Mean & Min & Max & $\mathrm{SD}$ & Mean & Min & Max & $\mathrm{SD}$ & Mean & Min & Max & SD \\
\hline WBC & 7.57 & 3.4 & 11.5 & 2.4 & 7.7 & 5.2 & 10.7 & 1.79 & 7.63 & 5.1 & 10.1 & 1.47 \\
\hline LYM & 2.16 & 1.2 & 3.5 & 0.72 & 2.32 & 1.8 & 3.4 & 0.59 & 2.26 & 1.5 & 3.4 & 0.58 \\
\hline LYM (\%) & 30.63 & 14.5 & 42.3 & 8.9 & 31.1 & 19.7 & 43.8 & 6.65 & 30.68 & 14.9 & 38.8 & 6.60 \\
\hline MID & 0.462 & 0.2 & 0.9 & 0.20 & 0.43 & 0.3 & 0.6 & 0.08 & 0.44 & 0.3 & 0.6 & 0.09 \\
\hline MID (\%) & 6.82 & 4.58 & 10 & 1.41 & 6.66 & 5.1 & 9.4 & 1.20 & 6.83 & 5.6 & 9.2 & 1.08 \\
\hline GRA & 4.92 & 1.8 & 8.3 & 2.01 & 4.94 & 2.9 & 7.2 & 1.49 & 4.93 & 3.1 & 8.1 & 1.35 \\
\hline GRA (\%) & 61.52 & 50.6 & 82.7 & 10.04 & 62.23 & 49.6 & 75.2 & 7.25 & 62.48 & 54.4 & 79.5 & 6.99 \\
\hline $\mathrm{RBC}$ & 4.56 & 4.13 & 5.36 & 0.419 & 4.61 & 4.25 & 5.42 & 0.39 & 4.66 & 4.28 & 5.38 & 0.38 \\
\hline $\mathrm{HGB}(\mathrm{g} / \mathrm{dl})$ & 12.7 & 10.6 & 15.2 & 1.49 & 12.73 & 10.4 & 15 & 1.56 & 12.84 & 9.8 & 15.7 & 1.87 \\
\hline HCT & 38.6 & 33.1 & 43.9 & 3.9 & 38.5 & 31.3 & 45.1 & 4.29 & 38.5 & 29.2 & 46.9 & 5.07 \\
\hline MCV (fl) & 85 & 65.4 & 94.2 & 8.20 & 83.71 & 60.6 & 93 & 9.41 & 83.51 & 60.5 & 92.7 & 9.39 \\
\hline $\mathrm{MCH}(\mathrm{pg})$ & 28.11 & 20.9 & 31.8 & 3.09 & 27.68 & 20.1 & 31.5 & 3.31 & 27.95 & 20.4 & 31.7 & 3.46 \\
\hline $\mathrm{MCHC}(\mathrm{g} / \mathrm{dl})$ & 32.92 & 31.2 & 34.7 & 1.03 & 33.03 & 31.2 & 34 & 0.95 & 33.44 & 31 & 36 & 1.44 \\
\hline RDWa (fl) & 44.33 & 12.9 & 56.8 & 17.2 & 52.7 & 37.5 & 60.4 & 6.48 & 52.38 & 38 & 60.7 & 6.44 \\
\hline RDWa (\%) & 13.01 & 11.6 & 16.5 & 1.52 & 13.07 & 12.1 & 14.4 & 0.88 & 13.1 & 11.8 & 14.4 & 1.01 \\
\hline PLT & 234.9 & 136 & 341 & 66.9 & 239.6 & 150 & 319 & 59.5 & 234.8 & 149 & 320 & 49.6 \\
\hline MPV (fl) & 9.26 & 8 & 10.2 & 0.72 & 9.12 & 7.7 & 10.1 & 0.87 & 9.14 & 8 & 10 & 0.63 \\
\hline PDWa (fl) & 21.31 & 10.9 & 60.7 & 18.1 & 12.31 & 10.3 & 13.5 & 1.22 & 12.44 & 10.8 & 13.3 & 0.84 \\
\hline PDWa (\%) & 0.21 & 0.13 & 0.32 & 0.06 & 0.215 & 0.15 & 0.31 & 0.05 & 0.22 & 0.13 & 0.33 & 0.06 \\
\hline PCT & 22.91 & 14.7 & 30.7 & 5.52 & 22.03 & 12.4 & 28.4 & 6.32 & 22.8 & 14.2 & 28.7 & 4.59 \\
\hline P-LCR & 7.57 & 3.4 & 11.5 & 2.47 & 7.7 & 5.2 & 10.7 & 1.79 & 21.33 & 13 & 38 & 7.8 \\
\hline B. urea $(\mathrm{mg} / \mathrm{dl})$ & 20.33 & 13 & 32 & 6.09 & 22.4 & 13 & 34 & 6.87 & 0.63 & 0.5 & 0.8 & 0.1 \\
\hline S. creatinine $(\mathrm{mg} / \mathrm{dl})$ & 0.7 & 0.5 & 0.8 & 0.09 & 0.64 & 0.5 & 0.8 & 0.11 & 58.66 & 45 & 74 & 9.0 \\
\hline ALK. Phosphatase (IU/L) & 56.33 & 43 & 74 & 11.74 & 49.11 & 39 & 59 & 7.97 & 19.13 & 14 & 23 & 3.02 \\
\hline GOT (AST) (IU/L) & 18.22 & 14 & 22 & 2.31 & 21 & 13 & 33 & 6.21 & 17.86 & 9.8 & 44 & 10.1 \\
\hline GPT (ALT) (IU/L) & 13.77 & 10 & 18 & 2.64 & 17.55 & 10 & 26 & 5.65 & 23.77 & 13 & 29 & 4.91 \\
\hline Gamma GT (GGT) (IU/L) & 13.11 & 8 & 18 & 3.70 & 22.11 & 11 & 35 & 7.18 & 4.01 & 3.7 & 4.9 & 0.36 \\
\hline S. albumin $(\mathrm{g} / \mathrm{dL})$ & 4.47 & 3.7 & 5.2 & 0.59 & 3.97 & 3.2 & 4.5 & 0.42 & 9.02 & 6.7 & 11.5 & 1.70 \\
\hline S. total protein $(\mathrm{mg} / \mathrm{dl})$ & 7.077 & 6.4 & 8.4 & 0.78 & 9.44 & 6.8 & 10.4 & 0.80 & 9.64 & 9.1 & 10.17 & 0.35 \\
\hline Total calcium $(\mathrm{mg} / \mathrm{dl})$ & 9.3 & 8.6 & 10.1 & 0.58 & 9.59 & 9.06 & 10.1 & 0.33 & 4.19 & 3.83 & 4.92 & 0.35 \\
\hline Potassium (mmol/l) & 4.14 & 3.57 & 5.1 & 0.46 & 3.98 & 3.5 & 4.6 & 0.35 & 140.7 & 126 & 152.1 & 5.63 \\
\hline Sodium (mmol/l) & 139.9 & 138 & 149.1 & 3.42 & 140.3 & 137.7 & 143.9 & 2.21 & 111.8 & 105.9 & 123.2 & 5.01 \\
\hline Chloride (mmol/l) & 111.63 & 108 & 122.5 & 4.25 & 112.18 & 108 & 117.4 & 3.28 & 2.37 & 0.34 & 7.94 & 2.29 \\
\hline C-reactive protein $(\mathrm{Mg} / \mathrm{l})$ & 2.08 & 0.13 & 6.99 & 2.57 & 2.43 & 0.04 & 10.76 & 3.18 & 7.63 & 5.1 & 10.1 & 1.47 \\
\hline
\end{tabular}

catabolism rate, extravascular distribution, and exogenous loss. Moreover, both nutritional status and systemic inflammation affect the synthesis of serum albumin. It is of interest to understand the prognostic value in the full spectrum of cardiovascular disease in the era of newly developed pharmacological and interventional treatments. As illustrated in the results, it is significantly dropped after 24 hours following submucosal injection of PRP [23], as albumin production may be inhibited by proinflammatory mediators [24].

Fifthly, serum proteins are mainly synthesized in the liver and, among other functions, maintain blood volume through the colloidal osmotic effect, buffer blood $\mathrm{pH}$, transport hormones and drugs, participate in cell coagulation, catalyze chemical reactions (enzymes), regulate the metabolism (hormones), and participate in the body's defense against foreign agents [25]. A rise in protein levels is noted in dehydration, amyloidosis, and chronic inflammatory states [26].

Alongside the total serum protein level, the albumin to globulin $(A / G)$ ratio in the bloodstream can be calculated in a laboratory. This is because some conditions affect the amounts of albumin or globulin in the blood. A low A/G ratio may be due to an overproduction of globulin, underproduction of albumin, or loss of albumin, which may indicate the following: an autoimmune disease, cirrhosis involving inflammation and scarring of the liver, multiple myeloma, and nephrotic syndrome, a kidney disease [27].

Lastly, calcium concentration is characterized by a high physiological variation, depending on age, sex, physiological state, and even season (owing to the seasonal variation of vitamin $\mathrm{D}$, which is directly involved in the regulation of calcium concentration). Unless serum proteins contain abnormalities, total serum calcium concentration is normally between 8.5 and $10.2 \mathrm{mg} / \mathrm{dl}$ of serum. Because ionized calcium is the only component of the total serum calcium level that is regulated by calciotropic hormones, decisions on the total serum calcium concentration should not be made unless changes in concentrations of plasma proteins, particularly albumin, are considered [28]. So, a common cause of elevated serum calcium is secondary to increased serum binding protein. Calcium levels are dictated by the actions of parathyroid hormone (PTH), calcitonin, and calcitriol. PTH levels rise and fall in response to serum calcium levels. High 
TABLE 2: Comparison of blood parameters before and after 24 hours and 7 days following PRP injection.

\begin{tabular}{|c|c|c|c|c|c|c|c|c|}
\hline & Blood markers & Normal level & Time & No. & Mean & $\mathrm{SD}$ & $F$-ratio & $p$ value \\
\hline & & & Tb0 & & 7.578 & 2.47 & & \\
\hline \multirow[t]{3}{*}{1} & WBC & $4.0-10.010^{9} / \mathrm{L}$ & $\mathrm{Tb} 1$ & 18 & 7.7 & 1.79 & 0.01746 & 0.98 \\
\hline & & & Tb7 & & 7.633 & 1.47 & & \\
\hline & & & Tb0 & & 2.161 & 0.73 & & \\
\hline \multirow[t]{3}{*}{2} & LYM & $1.0-3.510^{9} / \mathrm{L}$ & Tb1 & 18 & 2.32 & 0.59 & 0.297 & 0.743 \\
\hline & & & $\mathrm{Tb} 7$ & & 2.267 & 1.5 & & \\
\hline & & & Tb0 & & 30.7 & 8.9 & & \\
\hline \multirow[t]{3}{*}{3} & LYM\% & $2.0-45.0 \%$ & $\mathrm{~Tb} 1$ & 18 & 31.1 & 6.65 & 0.0209 & 0.979 \\
\hline & & & $\mathrm{Tb} 7$ & & 30.7 & 6.6 & & \\
\hline & & & Tb0 & & 0.47 & 0.2 & & \\
\hline \multirow[t]{3}{*}{4} & MID & $0.2-1.010^{9} / \mathrm{L}$ & Tb1 & 18 & 0.43 & 0.08 & 0.199 & 0.819 \\
\hline & & & $\mathrm{Tb} 7$ & & 0.44 & 0.1 & & \\
\hline & & & Tb0 & & 6.84 & 1.42 & & \\
\hline \multirow[t]{3}{*}{5} & MID\% & $2.0-10.0 \%$ & Tb1 & 18 & 4.96 & 1.21 & 0.1019 & 0.903 \\
\hline & & & $\mathrm{Tb} 7$ & & 61.5 & 1.09 & & \\
\hline & & & Tb0 & & 4.96 & 2.02 & & \\
\hline \multirow[t]{3}{*}{6} & GRA & $2.5-8.010^{9} / \mathrm{L}$ & $\mathrm{Tb} 1$ & 18 & 4.94 & 1.5 & 0.0007 & 0.999 \\
\hline & & & $\mathrm{Tb} 7$ & & 4.93 & 1.36 & & \\
\hline & & & Tb0 & & 61.5 & 10.05 & & \\
\hline \multirow[t]{3}{*}{7} & GRA\% & $40-80 \%$ & Tb1 & 18 & 62.2 & 7.25 & 0.066 & 0.936 \\
\hline & & & $\mathrm{Tb} 7$ & & 62.5 & 6.99 & & \\
\hline & & & Tb0 & & 4.56 & 0.42 & & \\
\hline \multirow[t]{3}{*}{8} & $\mathrm{RBC}$ & $4.5-5.5010^{12} / \mathrm{L}$ & Tb1 & 18 & 4.62 & 0.4 & 0.282 & 0.75 \\
\hline & & & Tb7 & & 4.66 & 0.38 & & \\
\hline & & & Tb0 & & 12.7 & 1.5 & & \\
\hline \multirow[t]{3}{*}{9} & HGB & $13.0-17.0 \mathrm{~g} / \mathrm{dl}$ & Tb1 & 18 & 12.7 & 1.57 & 0.03 & 0.963 \\
\hline & & & $\mathrm{Tb} 7$ & & 12.8 & 1.87 & & \\
\hline & & & Tb0 & & 38.6 & 3.9 & & \\
\hline \multirow[t]{3}{*}{10} & HCT & $40-50 \%$ & $\mathrm{~Tb} 1$ & 18 & 38.5 & 4.29 & 0.0037 & 0.996 \\
\hline & & & $\mathrm{Tb} 7$ & & 38.5 & 5.07 & & \\
\hline & & & Tb0 & & 85 & 8.2 & & \\
\hline \multirow[t]{3}{*}{11} & $\mathrm{MCV}$ & $80-100 \mathrm{fl}$ & Tb1 & 18 & 83.7 & 9.4 & 0.144 & 0.865 \\
\hline & & & $\mathrm{Tb} 7$ & & 83.5 & 9.3 & & \\
\hline & & & Tb0 & & 28 & 3.09 & & \\
\hline \multirow[t]{3}{*}{12} & $\mathrm{MCH}$ & $27-32 \mathrm{pg}$ & $\mathrm{Tb} 1$ & 18 & 27.7 & 3.32 & 0.077 & 0.925 \\
\hline & & & $\mathrm{Tb} 7$ & & 28 & 3.46 & & \\
\hline & & & Tb0 & & 32.9 & 1.03 & & \\
\hline \multirow[t]{3}{*}{13} & $\mathrm{MCHC}$ & $31-35 \mathrm{~g} / \mathrm{dl}$ & $\mathrm{Tb} 1$ & 18 & 33 & 0.095 & 0.99 & 0.378 \\
\hline & & & $\mathrm{Tb} 7$ & & 33.4 & 1.44 & & \\
\hline & & & Tb0 & & 44.4 & 17.3 & & \\
\hline \multirow[t]{3}{*}{14} & RDWa & $30-150 \mathrm{fl}$ & Tb1 & 18 & 52.7 & 6.48 & 3.17 & 0.50 \\
\hline & & & $\mathrm{Tb} 7$ & & 52.4 & 6.44 & & \\
\hline & & & Tb0 & & 13 & 1.53 & & \\
\hline 15 & RDWa\% & $11-16 \%$ & $\mathrm{~Tb} 1$ & 18 & 13.1 & 0.89 & 0.027 & 0.972 \\
\hline & & & Tb7 & & 13.1 & 1.01 & & \\
\hline & & & Tb0 & & 235 & 66.9 & & \\
\hline 16 & PLT & $100-40010^{9} / \mathrm{L}$ & Tb1 & 18 & 240 & 59.6 & 0.038 & 0.962 \\
\hline & & & $\mathrm{Tb} 7$ & & 234 & 49.6 & & \\
\hline & & & Tb0 & & 9.24 & 0.73 & & \\
\hline 17 & MPV & $7.0-11.0 \mathrm{fl}$ & $\mathrm{Tb} 1$ & 18 & 9.12 & 0.87 & 0.178 & 0.837 \\
\hline & & & $\mathrm{Tb} 7$ & & 9.14 & 0.63 & & \\
\hline & & & $\mathrm{Tb} 0$ & & 21.3 & 18.1 & & \\
\hline 18 & PDWa & $0.1-99.9 \mathrm{fl}$ & Tb1 & 18 & 12.3 & 1.22 & 4.33 & $0.018^{*}$ \\
\hline & & & $\mathrm{Tb} 7$ & & 12.4 & 0.84 & & \\
\hline & & & $\mathrm{Tb} 0$ & & 0.21 & 0.07 & & \\
\hline 19 & PCT & $0.01-9.99 \%$ & Tb1 & 18 & 0.22 & 0.05 & 0.17 & 0.84 \\
\hline & & & $\mathrm{Tb} 7$ & & 0.23 & 0.06 & & \\
\hline & & & Tb0 & & 22.7 & 5.53 & & \\
\hline 20 & P-LCR & $0.1-99.9 \%$ & $\mathrm{~Tb} 1$ & 18 & 22 & 6.32 & 0.134 & 0.874 \\
\hline & & & $\mathrm{Tb7}$ & & 22.8 & 4.59 & & \\
\hline
\end{tabular}


TABle 2: Continued.

\begin{tabular}{|c|c|c|c|c|c|c|c|c|}
\hline & Blood markers & Normal level & Time & No. & Mean & $\mathrm{SD}$ & F-ratio & $p$ value \\
\hline & & & Tb0 & & 20.3 & 6.1 & & \\
\hline \multirow[t]{3}{*}{21} & B. urea & $16-48 \mathrm{mg} / \mathrm{dl}$ & Tb1 & 18 & 22.4 & 6.88 & 0.41 & 0.66 \\
\hline & & & $\mathrm{Tb} 7$ & & 21.3 & 7.81 & & \\
\hline & & & Tb0 & & 0.7 & 0.1 & & \\
\hline \multirow[t]{3}{*}{22} & S. creatinine & $0.6-1.3 \mathrm{mg} / \mathrm{dl}$ & Tb1 & 18 & 0.64 & 0.12 & 1.81 & 0.172 \\
\hline & & & $\mathrm{Tb} 7$ & & 0.63 & 0.12 & & \\
\hline & & & Tb0 & & 56.3 & 11.7 & & \\
\hline \multirow[t]{3}{*}{23} & ALK. phosphate & 20-140 IU/L & Tb1 & 18 & 49.1 & 7.98 & 4.74 & $0.013^{*}$ \\
\hline & & & $\mathrm{Tb} 7$ & & 58.7 & 9.01 & & \\
\hline & & & Tb0 & & 18.2 & 2.32 & & \\
\hline \multirow[t]{3}{*}{24} & GOT (AST) & $<32 \mathrm{IU} / \mathrm{L}$ & Tb1 & 18 & 21 & 6.21 & 2.03 & 0.14 \\
\hline & & & Tb7 & & 19.1 & 3.02 & & \\
\hline & & & Tb0 & & 13.8 & 2.65 & & \\
\hline \multirow[t]{3}{*}{25} & GPT (ALT) & $<30 \mathrm{IU} / \mathrm{L}$ & Tb1 & 18 & 17.6 & 5.66 & 1.96 & 0.15 \\
\hline & & & $\mathrm{Tb} 7$ & & 17.9 & 10.2 & & \\
\hline & & & Tb0 & & 13.1 & 3.71 & & \\
\hline \multirow[t]{3}{*}{26} & Gamma GT (GGT) & $0-30 \mathrm{IU} / \mathrm{L}$ & $\mathrm{Tb} 1$ & 18 & 22.1 & 7.19 & 19.85 & $0.00001^{*}$ \\
\hline & & & Tb7 & & 23.8 & 4.92 & & \\
\hline & & & Tb0 & & 4.48 & 0.6 & & \\
\hline \multirow[t]{3}{*}{27} & S. albumin & $3.5-5.2 \mathrm{~g} / \mathrm{dl}$ & Tb1 & 18 & 3.98 & 0.42 & 6.33 & $0.0035^{*}$ \\
\hline & & & $\mathrm{Tb} 7$ & & 4.01 & 0.36 & & \\
\hline & & & Tb0 & & 7.08 & 0.78 & & \\
\hline \multirow[t]{3}{*}{28} & S. total protein & $6.4-8.3 \mathrm{~g} / \mathrm{dl}$ & Tb1 & 18 & 9.44 & 0.8 & 20.66 & $0.00001^{*}$ \\
\hline & & & $\mathrm{Tb} 7$ & & 9.02 & 1.7 & & \\
\hline & & & Tb0 & & 9.3 & 0.58 & & \\
\hline \multirow[t]{3}{*}{29} & Total calcium & $8.6-10.2 \mathrm{mg} / \mathrm{dl}$ & Tb1 & 18 & 9.59 & 0.34 & 3.21 & $0.049^{*}$ \\
\hline & & & $\mathrm{Tb} 7$ & & 9.65 & 0.35 & & \\
\hline & & & Tb0 & & 4.14 & 0.46 & & \\
\hline \multirow[t]{3}{*}{30} & Potassium (K) & $3.5-5.1 \mathrm{mmol} / \mathrm{L}$ & Tb1 & 18 & 3.98 & 0.35 & 1.47 & 0.239 \\
\hline & & & $\mathrm{Tb} 7$ & & 4.2 & 0.35 & & \\
\hline & & & Tb0 & & 140 & 3.43 & & \\
\hline \multirow[t]{3}{*}{31} & Sodium $(\mathrm{Na})$ & $136-145 \mathrm{mmol} / \mathrm{L}$ & Tb1 & 18 & 140 & 2.22 & 0.179 & 0.836 \\
\hline & & & Tb7 & & 140 & 5.64 & & \\
\hline & & & Tb0 & & 112 & 4.25 & & \\
\hline \multirow[t]{3}{*}{32} & Chloride (Cl) & $95-115 \mathrm{mmol} / \mathrm{L}$ & Tb1 & 18 & 112 & 3.29 & 0.077 & 0.925 \\
\hline & & & $\mathrm{Tb} 7$ & & 112 & 5.01 & & \\
\hline & & & $\mathrm{Tb} 0$ & & 2.08 & 2.58 & & \\
\hline \multirow[t]{2}{*}{33} & C-reactive protein (CRP) & $<6.0 \mathrm{mg} / \mathrm{L}$ & Tb1 & & 2.44 & 3.19 & 0.088 & 0.915 \\
\hline & & & $\mathrm{Tb} 7$ & & 2.38 & 2.29 & & \\
\hline
\end{tabular}

levels of PTH stimulate a rise in serum calcium by increasing both renal tubular calcium reabsorption and bone resorption. PTH also stimulates the conversion of calcidiol to calcitriol in the kidneys. Calcitriol leads to a further increase in serum calcium via increased absorption of calcium in the small intestine. Phosphate metabolism is also controlled by PTH and calcitriol; PTH generally lowers phosphate levels through its effects on the kidney, while calcitriol generally raises phosphate levels through its effects on the intestine and inhibitory effects on PTH levels. Liver recovery is an extremely complicated process that involves intercellular interaction between growth factors and cytokines [28].

No previous study was associated with the effect of PRP on the liver. Salem et al. described the regenerative impact of platelets in the liver of adult male Wistar rats, which comprises three pathways: a direct impact on hepatocytes, a favorable impact on liver sinusoidal endothelial cells, and a collaborative impact on Kupffer cells [29]. Therefore, it was proposed that the expansion of platelets induced by platelet transfusion would enhance liver functions in patients with chronic liver diseases in the clinical setting [30]. Growth factors and cytokines cause activation of downstream cascades, related to the advancement of quiescent hepatocytes into the cell cycle.

All the blood parameters that have been significantly altered after submucosal injection of PRP are related to liver function; hereby, we can correlate these findings to the following: although PRP is locally injected, it has systematic influence by induction of inflammation of vital structures such as the liver and kidney which gives rise to a serious question: can PRP cause systematic adverse effects? However, PRP is locally used in dentistry or for dermatological purposes. Again, a question concerning patients already having liver problems arises: are they suitable for PRP therapy? So, further investigation is needed for a larger sample size within different age groups to verify the systematic effect of local PRP injection for a longer duration and repeated injection cases. 


\section{Conclusion}

Submucosal injection of PRP could lead to systematic alteration of blood parameters including ALK phosphatase, gamma GT, S. albumin, and S. total protein, which may be related to liver function impairment, in addition to increase in the level of PDWa and calcium.

\section{Abbreviation}

\begin{tabular}{|c|c|}
\hline WBC: & White blood cells \\
\hline LYM: & Lymphocyte \\
\hline LYM\%: & Lymphocyte percentage \\
\hline MID: & $\begin{array}{l}\text { Rare cells correlating to monocytes, } \\
\text { eosinophils, basophils, blasts, and other } \\
\text { precursor white cells that fall in a particular } \\
\text { size range. }\end{array}$ \\
\hline MID\%: & MID as percentage \\
\hline GRA: & $\begin{array}{l}\text { Granulocytes (neutrophils, monocytes, } \\
\text { basophils, and eosinophils) }\end{array}$ \\
\hline GRA\%: & Granulocytes as percentage \\
\hline RBC: & Red blood cells \\
\hline HGB: & Hemoglobin \\
\hline HCT: & Hematocrit \\
\hline MCV: & Mean corpuscular volume \\
\hline MCH: & Mean corpuscular haemoglobin \\
\hline MCHC: & $\begin{array}{l}\text { Mean corpuscular haemoglobin } \\
\text { concentration }\end{array}$ \\
\hline RDWa: & Red blood cell distribution width average \\
\hline RDWa\%: & Red cell distribution width as percentage \\
\hline PLT: & Platelets \\
\hline MPV: & Mean platelet volume \\
\hline PDWa: & Platelet distribution width \\
\hline PDWa\%: & Platelet distribution width as percentage \\
\hline PCT: & Procalcitonin \\
\hline P-LCR: & Platelet larger cell ratio \\
\hline B. urea: & Blood urea \\
\hline S. creatinine: & Serum creatinine \\
\hline ALK & Alkaline phosphatase \\
\hline Phosphate: & \\
\hline GOT (AST): & Aspartate aminotransferase \\
\hline GPT (ALT): & Aspartate aminotransferase \\
\hline $\begin{array}{l}\text { Gamma GT } \\
(\text { GGT): }\end{array}$ & Gamma-glutamyl transferase \\
\hline S. albumin: & Serum albumin \\
\hline $\begin{array}{l}\text { S. total } \\
\text { protein: }\end{array}$ & Serum total protein \\
\hline CRP: & C-reactive protein \\
\hline
\end{tabular}

\section{Data Availability}

The presented data are part of a Ph.D. thesis by Trefa Mohammad Ali Mahmood, College of Dentistry, University of Sulaimani, Kurdistan Region.

\section{Additional Points}

This is the first and only adequately powered study of the systemic effects of PRP. No previous study has been conducted revealing the effect of submucosal injection of PRP on the systemic blood markers which may interfere with some systemic diseases or cause other serious complications.

\section{Conflicts of Interest}

The authors declare that they have no conflicts of interest.

\section{Acknowledgments}

The authors sincerely thank the College of Dentistry, University of Sulaimani, for supporting the project, and thanks are due to the staff of the Specialized Center of DermoDento Center and Shar Laboratory Center for their help to carry out this work.

\section{References}

[1] U. Mangal, "Influence of platelet rich plasma on orthodontic tooth movement: a review," Biomedical and Pharmacology Journal, vol. 10, no. 3, pp. 1463-1468, 2017.

[2] F. Zotti, M. Albanese, L. Rodella, and P. Nocini, "Platelet-rich plasma in treatment of temporomandibular joint dysfunctions: narrative review," International Journal of Molecular Sciences, vol. 20, no. 2, p. 277, 2019.

[3] R. Alves and R. Grimalt, "A review of platelet-rich plasma: history, biology, mechanism of action, and classification," Skin Appendage Disorders, vol. 4, no. 1, pp. 18-24, 2018.

[4] R. E. Marx, "Platelet-rich plasma (PRP): what is PRP and what is not PRP?," Implant Dentistry, vol. 10, no. 4, pp. 225-228, 2001.

[5] R. E. Marx, "Platelet-rich plasma: evidence to support its use," Journal of Oral and Maxillofacial Surgery, vol. 62, no. 4, pp. 489-496, 2004.

[6] A. Güleç, B. Ç. Bakkalbaşı, A. Cumbul, Ü. Uslu, B. Alev, and A. Yarat, "Effects of local platelet-rich plasma injection on the rate of orthodontic tooth movement in a rat model: a histomorphometric study," American Journal of Orthodontics and Dentofacial Orthopedics, vol. 151, no. 1, pp. 92-104, 2017.

[7] D. Yashin, O. Dalci, M. Almuzian et al., "Markers in blood and saliva for prediction of orthodontically induced inflammatory root resorption: a retrospective case controlledstudy," Progress in Orthodontics, vol. 18, no. 1, p. 27, 2017.

[8] Z. Ileri, M. Akin, E. A. Erdur, H. T. Dagi, and D. Findik, "Bacteremia after piezocision," American Journal of Orthodontics and Dentofacial Orthopedics, vol. 146, no. 4, pp. 430-436, 2014.

[9] M. Azeem, A. Ul Haq, M. Ilyas et al., "Bacteremia after microosteoperforation," International Orthodontics, vol. 16, no. 3, pp. 463-469, 2018.

[10] J. C. Greene and J. R. Vermillion, "The oral hygiene index: a method for classifying oral hygiene status," The Journal of American Dental Association, vol. 61, no. 2, pp. 172-179, 1960.

[11] R. Hegde, "Effects of periodontal therapy on systemic markers in healthy patients," Journal of Dentistry and Oral Biology, vol. 2 , no. 8, p. 1055, 2017.

[12] R. Kanuru, B. Kolasani, V. Narayana, R. Indukuri, M. Azaneen, and F. Babu, "Comparison of canine retraction by in vivo method using four brands of elastomeric power chain," Journal of International Society of Preventive and Community Dentistry, vol. 4, no. 4, pp. 32-37, 2014. 
[13] J. Fitzpatrick, M. K. Bulsara, P. R. McCrory, M. D. Richardson, and M. H. Zheng, "Analysis of platelet-rich plasma extraction: variations in platelet and blood components between 4 common commercial kits," Orthopaedic Journal of Sports Medicine, vol. 5, no. 1, Article ID 232596711667527, 2017.

[14] R. Dhurat and M. S. Sukesh, "Principles and methods of preparation of platelet-rich plasma: a review and author's perspective," Journal of Cutaneous and Aesthetic Surgery, vol. 7, no. 4, pp. 189-197, 2014.

[15] E. W. Liou, "The development of submucosal injection of platelet rich plasma for accelerating orthodontic tooth movement and preserving pressure side alveolar bone," APOS Trends in Orthodontics, vol. 6, no. 1, pp. 5-11, 2016.

[16] A. A. Amin, A. N. Arf, and Z. J. Rashid, "Angle's classification of first molar occlusion among patients attending a private orthodontic clinic in Sulaimani City," Sulaimani Dental Journal, vol. 1, no. 2, pp. 91-93, 2014.

[17] J. K. MacLaine, A. B. M. Rabie, and R. Wong, "Does orthodontic tooth movement cause an elevation in systemic inflammatory markers?," The European Journal of Orthodontics, vol. 32, no. 4, pp. 435-440, 2010.

[18] F. Bilgic, O. Akinci Sozer, O. Ozcan, A. B. Gurpinar, H. Yilmaz, and Y. Ay, "Evaluation of inflammation during fixed orthodontic treatment," Archives of Oral Biology, vol. 71, pp. 54-58, 2016.

[19] G. Koenig and S. Seneff, "Gamma-glutamyltransferase: a predictive biomarker of cellular antioxidant inadequacy and disease risk," Disease markers, vol. 2015, Article ID 818570, 18 pages, 2015.

[20] J. Wang, L. Xing, J. Pu et al., "Association between gammaglutamyl transferase and coronary atherosclerotic plaque vulnerability: an optical coherence tomography study," BioMed Research International, vol. 2019, Article ID 9602783, 11 pages, 2019.

[21] F. T. Fischbach, Manual of Laboratory \& Diagnostic Tests, Lippincott Williams \& Wilkins, Philadelphia, PA, USA, 7th edition, 2003.

[22] J. Huizen, "What do abnormal ALP levels mean? Medical News Today. 2018, https://www.medicalnewstoday.com/ articles/321984.php.

[23] S. C. Chien, C. Y. Chen, C. F. Lin, and H. I. Yeh, "Critical appraisal of the role of serum albumin in cardiovascular disease," Biomarker Research, vol. 5, no. 1, p. 31, 2017.

[24] S. Cabrerizo, D. Cuadras, F. Gomez-Busto, I. Artaza-Artabe, F. Marín-Ciancas, and V. Malafarina, "Serum albumin and health in older people: review and meta analysis," Maturitas, vol. 81, no. 1, pp. 17-27, 2015.

[25] A. Melillo, "Applications of serum protein electrophoresis in exotic pet medicine," Veterinary Clinics of North America: Exotic Animal Practice, vol. 16, no. 1, pp. 211-225, 2013.

[26] M. Madhuvanthi and G. V. Lathadevi, "Serum proteins alteration in association with body mass index in human volunteers," Journal of Clinical and Diagnostic Research JCDR, vol. 10, no. 6, pp. CC05-CC07, 2016.

[27] J. Eske, "What to know about the protein test and results," Medical News Today, MediLexicon, Intl., 2019, https://www. medicalnewstoday.com/articles/.php.

[28] Clinical and Laboratory Standards Institute, C31-A2 Ionized Calcium Determinations: Precollection Variables, Specimen Choice, Collection, and Handling; Approved Guideline, Vol. 12, Clinical and Laboratory Standards Institute, Wayne, PA, USA, 2nd edition, 2001.

[29] N. A. Salem, A. Hamza, H. Alnahdi, and N. Ayaz, "Biochemical and molecular mechanisms of platelet-rich plasma in ameliorating liver fibrosis induced by dimethylnitrosurea," Cellular Physiology and Biochemistry, vol. 47, no. 6, pp. 2331-2339, 2018.

[30] K. Takahashi, S. Murata, and N. Ohkohchi, "Platelets and liver regeneration," Austin Journal of Surgery, vol. 1, no. 4, p. 1019, 2014. 


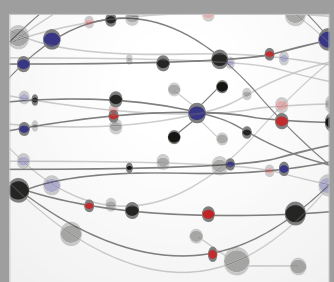

The Scientific World Journal
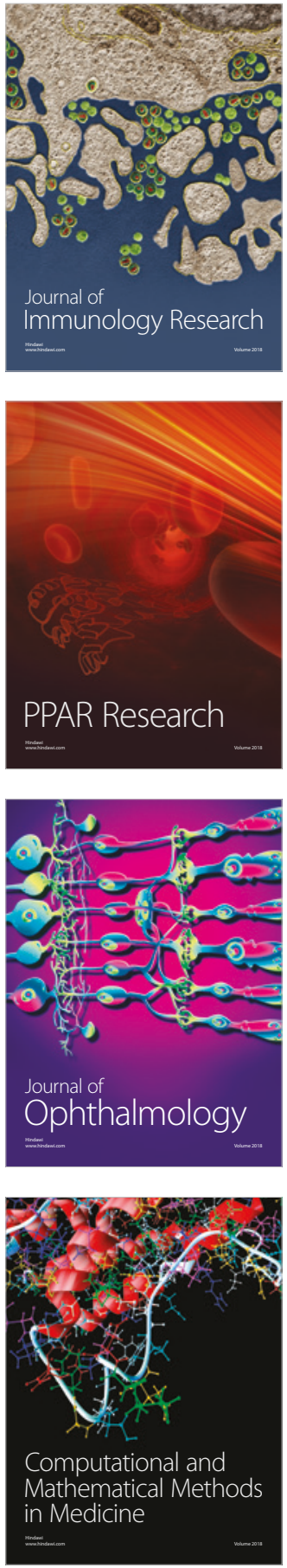

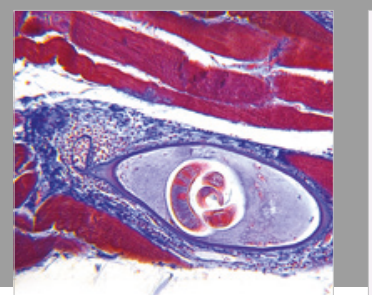

Gastroenterology Research and Practice

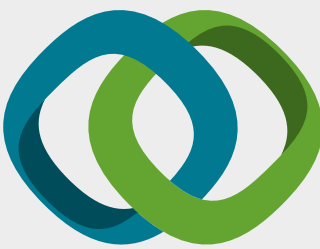

\section{Hindawi}

Submit your manuscripts at

www.hindawi.com
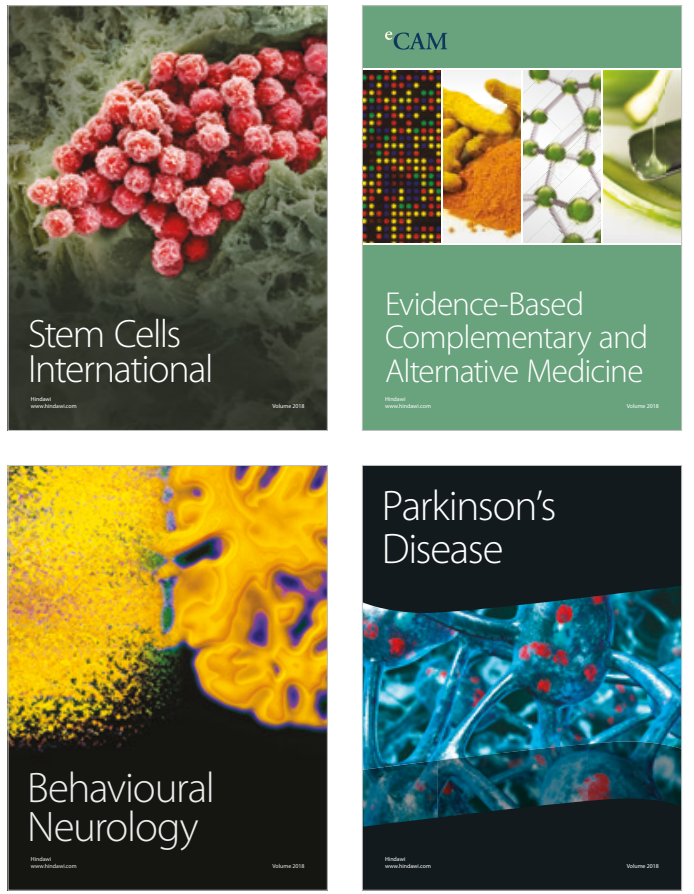

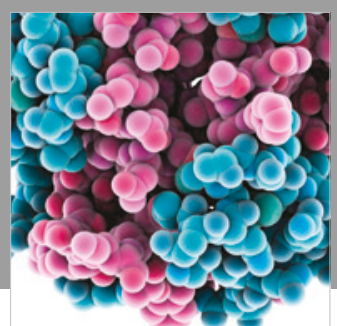

ournal of

Diabetes Research

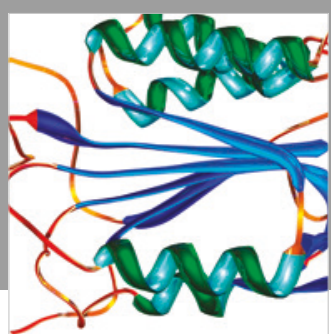

Disease Markers
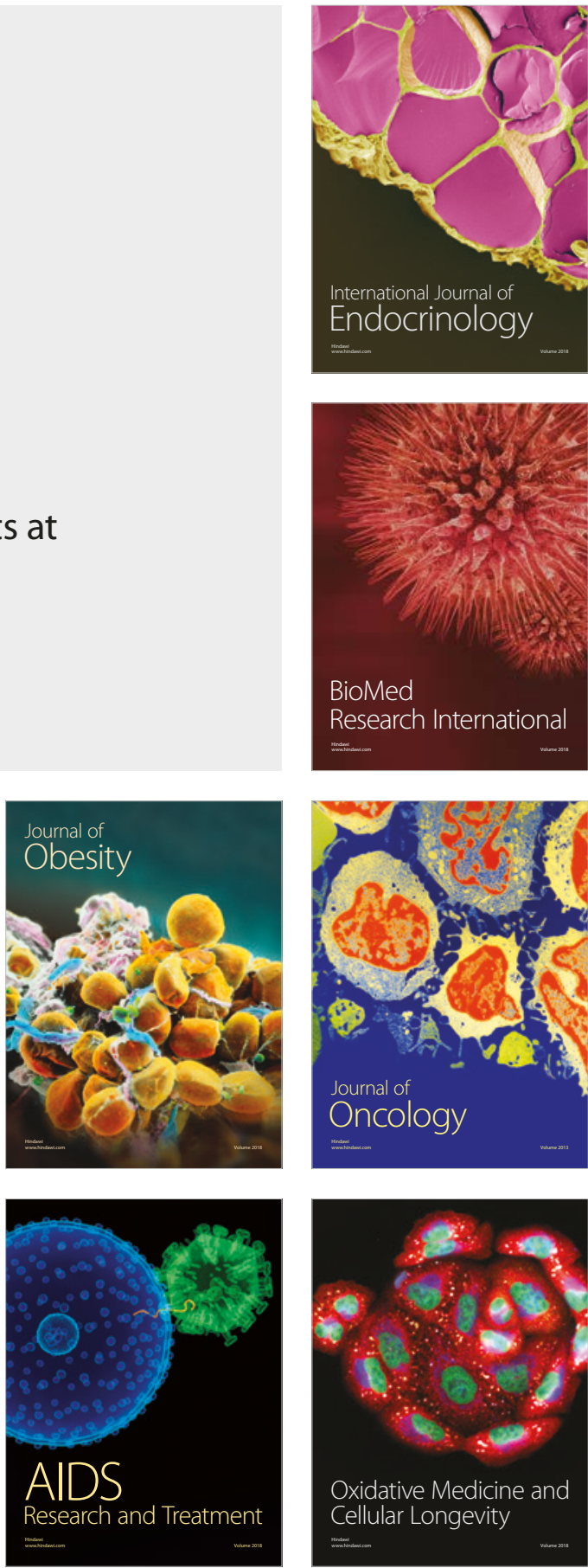